\title{
Engajamento e a adição ao trabalho em profissionais em Recursos Humanos
}

\author{
Claudia Duarte Vergara ${ }^{1, *}$, Augusto Gilmar Antunes Althoff², \\ Luana Giongo Pedrotti ${ }^{3}$, Ana Claudia Souza Vazquez ${ }^{4}$, Mônica Maria Celestina De Oliveira ${ }^{5}$
}

\footnotetext{
${ }^{1}$ https://orcid.org/0000-0001-5524-1467 - Universidade Federal de Ciências da Saúde de Porto Alegre (UFCSPA), Brasil

${ }^{2}$ https://orcid.org/0000-0003-0791-2638 - Universidade Federal do Rio Grande do Sul (UFRGS), Brasil

${ }^{3}$ https://orcid.org/0000-0001-9755-9019 - Universidade Federal do Rio Grande do Sul (UFRGS), Brasil

${ }^{4}$ https://orcid.org/0000-0002-7760-9266 - Universidade Federal de Ciências da Saúde de Porto Alegre (UFCSPA), Brasil

${ }^{5}$ https://orcid.org/0000-0002-5197-9103 - Universidade Federal de Ciências da Saúde de Porto Alegre (UFCSPA), Brasil
}

\section{Resumo}

O objetivo deste estudo foi avaliar o nível de engajamento e de adição ao trabalho e suas correlações com recursos pessoais, recursos do trabalho e demandas no trabalho em profissionais de Recursos Humanos (RH). Participaram 440 profissionais, 80\% do sexo feminino, das cinco regiões brasileiras. Os resultados sugerem que os profissionais de RH têm engajamento mediano, compatível com autoestima, otimismo, autoeficácia e esperança. Também apresentam nível de adição laboral médio, de modo que os achados demonstram que o trabalho excessivo e trabalho compulsivo é uma realidade da prática deles. Para a faixa etária acima dos 40 anos, o nível de engajamento demonstrou ser médio-inferior, algo contrário às expectativas para esta fase solidificação de carreira. Ademais, foi encontrada correlação positiva e fraca com a adição ao trabalho, o que sugere a influência do trabalho excessivo e compulsivo no modo de ativação de energia. Apresentamos sugestões de estudos futuros para avanços na área.

Palavras-chave: engajamento, adição ao trabalho, recursos humanos.

Engagement and the workaholism in human resources professionals

\section{El engajamiento y la adicción al trabajo en profesionales de recursos humanos}

\section{Abstract}

The main goal of this study was to evaluate the level of engagement and workaholism and its correlations with personal resources, job resources and job demands in Human Resources professionals. In this study, $440 \mathrm{HR}$ professionals participated, being 80\% women from Brazil's five region. The findings suggest that HR professionals show an average level of engagement with the work they do, which is compatible with self-esteem, optimism, self-efficacy and hope. Besides, they also show an average level of workaholism, which demonstrates that excessive and compulsive work is something real in their everyday routine. People over 40 years old showing a lower average level of engagement, which was unexpected since this age group is supposed to be solid careers. Moreover, a positive and weak correlation with workaholism was found, which suggests the influence of excessive and compulsive work at the way energy is activated. Suggestions are presented for further studies in the area.

Keywords: engagement, workaholism, human resources.

\section{Resumen}

El principal objetivo de este estudio fue el de evaluar el nivel de compromiso y de adicción al trabajo y sus correlaciones con recursos personales, recursos laborales y demandas en el trabajo en profesionales de recursos humanos. Participaron 440 profesionales, $80 \%$ sexo femenino, de las cinco regiones de Brasil. Los hallazgos sugieren que los profesionales de RH mostraron un nivel promedio de compromiso, compatible con autoestima, optimismo, autoeficacia y esperanza. También mostraron un nivel de adicción laboral promedio, lo que demuestra que el trabajo excesivo y compulsivo es una realidad en su rutina diaria. Para el grupo de edad superior a los 40 años, el nivel de compromiso demostró ser inferior en promedio algo contrario a las expectativas para esta fase solidificación de carrera. Además, se encontró una positiva y débil correlación con la adicción al trabajo, lo que sugiere la influencia del trabajo excesivo y compulsivo a la vez que es activada la energía. Se presentan sugerencias para estudios futuros en el área.

Palabras-clave: compromiso, adicción al trabajo, recursos humanos. 
O engajamento é um constructo que está diretamente relacionado ao bem-estar e à saúde ocupacional. Caracteriza profissionais que apresentam níveis elevados de vitalidade (vigor e energia), dedicação (persistência e orgulho) e concentração (absorção e apego) no trabalho (Schaufeli, 2018). O trabalhador engajado investe esforço e energia, porque o trabalho, para ele, tem um propósito, é visto de forma positiva e realizadora e não consiste apenas em uma obrigação ou em um modo de sobrevivência (Vazquez, Pacico, Magnan, Hutz, \& Schaufeli, 2016). Já a adição refere-se à forte compulsão e ao descontrole por trabalhar incessantemente, o que pode prejudicar a saúde e afetar negativamente a qualidade das relações pessoais e sociais (Taris, Van Beek, \& Schaufeli, 2014).

Engajamento e adição assemelham-se quanto aos níveis de energia que o trabalhador investe nas atividades laborais, sendo duas formas de investimento pesado no trabalho, diferenciando-se quanto ao bem-estar: ao contrário do engajado, o adicto apresenta baixos níveis de prazer (Salanova, Del Líbano, Llorens, \& Schaufeli, 2014; Taris et al., 2014). Não há estudos que testem empiricamente suas relações em profissionais brasileiros, apesar dos achados na literatura internacional. Além disso, também há carência de estudos sobre a relação entre essas variáveis e as características positivas das pessoas em suas atividades laborais. A presente pesquisa pretende contribuir para a compreensão dessa lacuna, especialmente no que diz respeito à saúde dos trabalhadores.

As bases para a teoria do engajamento no trabalho partem de pesquisas em saúde ocupacional e em Psicologia Positiva Organizacional e do Trabalho (PPOT), que visam estudar os aspectos saudáveis e positivos no trabalho. Dentre muitas definições, destaca-se a aplicada no modelo teórico de Recursos e Demandas do Trabalho (RDT), em que Schaufeli e Bakker (2010) defendem o papel mediador do engajamento no trabalho entre a combinação de recursos com as demandas laborais e o desempenho. Os autores demonstram, em seus estudos, que ele é um indicador de saúde do trabalhador. O Modelo de RDT considera que o engajamento pode ser potencializado pelo funcionamento ótimo no trabalho, abarcando os seguintes aspectos: 1) demandas, que são as exigências do trabalho, com possível fonte de estresse; 2) recursos externos, que são extrínsecos ao trabalhador e referem-se ao ambiente laboral e 3) recursos internos intrínsecos ao trabalhador, que são características da personalidade, conhecimentos, atitudes ou aptidões (Vazquez et al., 2016).

Estudos já realizados corroboraram a relação dos recursos e das demandas do trabalho com o engajamento, como os de Ouweneel, Le Blanc, e Schaufeli (2012). Eles identificaram reciprocidade entre emoções positivas e recursos pessoais de esperança, otimismo e autoeficácia ao engajamento no trabalho. Constataram que a autoeficácia se fortalece com emoções positivas no trabalho, mesmo não tendo apresentado relação significativa com recursos de trabalho. Demonstram que características de personalidade impulsionam o engajamento no processo motivacional relacionado ao trabalho, tais como resiliência e autoestima, entre outros.

Xanthopoulou, Bakker, Demerouti, e Schaufeli (2012) consideram que os recursos pessoais de autoestima, autoeficácia, otimismo e esperança são preditores do engajamento. A autoestima é o autoconceito de autoaprovação (positiva) ou de depreciação (negativo), por meio de pensamentos e sentimentos (Hutz, Zanon, \& Vazquez, 2014). A autoeficácia é a autoavaliação de que se é competente e eficaz nas ações realizadas (Pacico, Ferraz, \& Hutz, 2014). Otimismo é a expectativa e pensamento positivo individual quanto ao futuro (Bastianello \& Pacico, 2014), enquanto a esperança é capacidade e motivação do indivíduo para planejar rotas para atingir um objetivo (Pacico \& Bastianello, 2014). Para Seligman (2012), autoestima (sentimento positivo que o sujeito tem de si mesmo) e otimismo (sensação de que os maus acontecimentos são temporários, mutáveis e locais) são características essenciais que, em quantidades elevadas, geram o "florescimento", palavra que o autor usa para denominar bem-estar.

Por outro lado, os estudos de Schaufeli (2016) evidenciaram a correlação entre personalidade e clima organizacional com adição ao trabalho (workaholic) e engajamento. Seus resultados demonstram que o neuroticismo e traços de instabilidade emocional, estão positivamente relacionados à adição ao trabalho e a um clima organizacional que demanda o trabalho em excesso e está negativamente relacionado ao engajamento, sendo esse associado a um clima que inspire desenvolvimento profissional.

Tendo em vista as robustas evidências dos achados no modelo de RDT e dos estudos em engajamento no trabalho, entende-se, na presente pesquisa, que é possível realizar uma análise das atividades dos profissionais que atuam em sistemas de Recursos Humanos (RH), conforme suas ações e seus propósitos. Seja por função, seja por cultura organizacional, os profissionais de RH são vistos nas empresas como os responsáveis por avaliar, analisar e promover um clima organizacional positivo. Tais profissionais também são considerados responsáveis por identificar recursos pessoais em processos seletivos e/ou desenvolver profissionais para que apresentem desempenho eficaz e boa produtividade.

Diante do exposto, o objetivo principal deste estudo foi identificar os níveis de engajamento, de adição ao trabalho e dos recursos pessoais de autoeficácia, otimismo, esperança e autoestima. Busca-se, com este estudo, verificar e analisar possíveis relações do engajamento dos profissionais com os recursos pessoais apontados no Modelo de RDT - autoeficácia, otimismo, esperança e autoestima, como também com a adição ao trabalho. Questiona-se qual a influência dos recursos pessoais e laborais, das demandas organizacionais e da adição laboral no engajamento no trabalho desses profissionais, que têm como desafio atuar em gestão de pessoas nas organizações.

\section{O Engajamento e a Adição no Trabalho}

O conceito de engajamento no trabalho não é novo na literatura científica, porém há diferentes modos de compreendê-lo. Nos estudos em Psicologia Positiva Organizacional e do Trabalho, profissionais são caracterizados em razão de verem o trabalho de forma positiva e realizadora, e isso está diretamente relacionado ao bem-estar e à saúde ocupacional (Vazquez et al., 2016).

Schaufeli e Bakker (2010) lançaram um conceito de engajamento, considerando a perspectiva dos RDT. Nessa abordagem, o engajamento é definido como um estado psicológico aplicado para o alcance de metas individuais de desempenho, com o qual o trabalhador faz o equilíbrio positivo entre o que é exigido pelas atividades profissionais (demandas), os seus recursos pessoais (cognição, emoção e comportamento) e os recursos sociais e organizacionais do trabalho (Schaufeli, 2018; Vazquez et al., 2016).

Schaufeli e Bakker (2004) propuseram, então, a Utrecht Work Engagement Scale (UWES), instrumento de mensuração dos níveis de engajamento, sendo a versão brasileira validada por Vazquez et al. (2016). Esses autores trabalham com a ideia de que o engajamento é mais do que uma antítese positiva do Burnout, doença caracterizada por esgotamento profissional, associado ao estresse, e em razão de sua caracterização como indicador de saúde do trabalho (Schaufeli, 2018). Para Vazquez et al. (2016), o engajamento é um fenômeno disposicional, que não pode ser definido como uma sensação momentânea, em que se deve reconhecer a influência do ambiente, ou em que o indivíduo se vincula baseado em valores e preferências internas. Sendo assim, é uma relação mais estável com o trabalho, mas que pode ser alterada diante da modificação das condições laborais. Ele deve ser enten- 
dido como um conceito independente e devidamente diferenciado dos conceitos de comprometimento organizacional, envolvimento em tarefas ou satisfação no trabalho (Schaufeli \& Bakker, 2004).

Dessa maneira, no Modelo de RDT, a ótima combinação de recursos e demandas do trabalho deve propiciar energia e prazer ao trabalhador, de modo a torná-lo engajado com seu trabalho. Para tal, além dos recursos físicos e de condições adequadas do ambiente de trabalho, fazem-se necessárias práticas e estratégias positivas de gestão, como apoio social e companheirismo dos colegas, feedback construtivo do supervisor, participação em atividades ou programas organizacionais de autodesenvolvimento, treinamentos, oportunidades de crescimento de carreira e maior autonomia em sua atuação profissional (Schaufeli, Dijkstra, \& Vazquez, 2013). A Figura 1 apresenta o Modelo de RDT e faz a relação entre processo motivacional (aspectos positivos) e processo de adoecimento (aspectos negativos): de duas formas: 1) as demandas do trabalho exigem uma conduta de adição ao trabalho, valorizando o workaholic e 2) as demandas estimulam a dedicação e a absorção ao trabalho pelo incentivo às práticas de crescimento e desenvolvimento, propiciando o engajamento (Schaufeli, 2016). A adição é uma forma negativa de investimento da força laboral, enquanto o engajamento representa um bom tipo de investimento em trabalho pesado (Schaufeli, 2016), associado a um estado de espírito positivo e ao bem-estar relacionado ao trabalho (Schaufeli \& Bakker, 2004). Desse modo, a adição ao trabalho é o termo para descrever a expressão americana workaholism, que tem origem na palavra alcoholic (alcoólatra) e foi utilizada para designar uma pessoa viciada em trabalho.

O workaholic investe excessiva energia e carga horária no trabalho por compulsão, o que caracteriza um tipo negativo de investimento ao trabalho que pode ter consequências nocivas para a saúde, tais como: problemas no sono, estresse, Burnout,

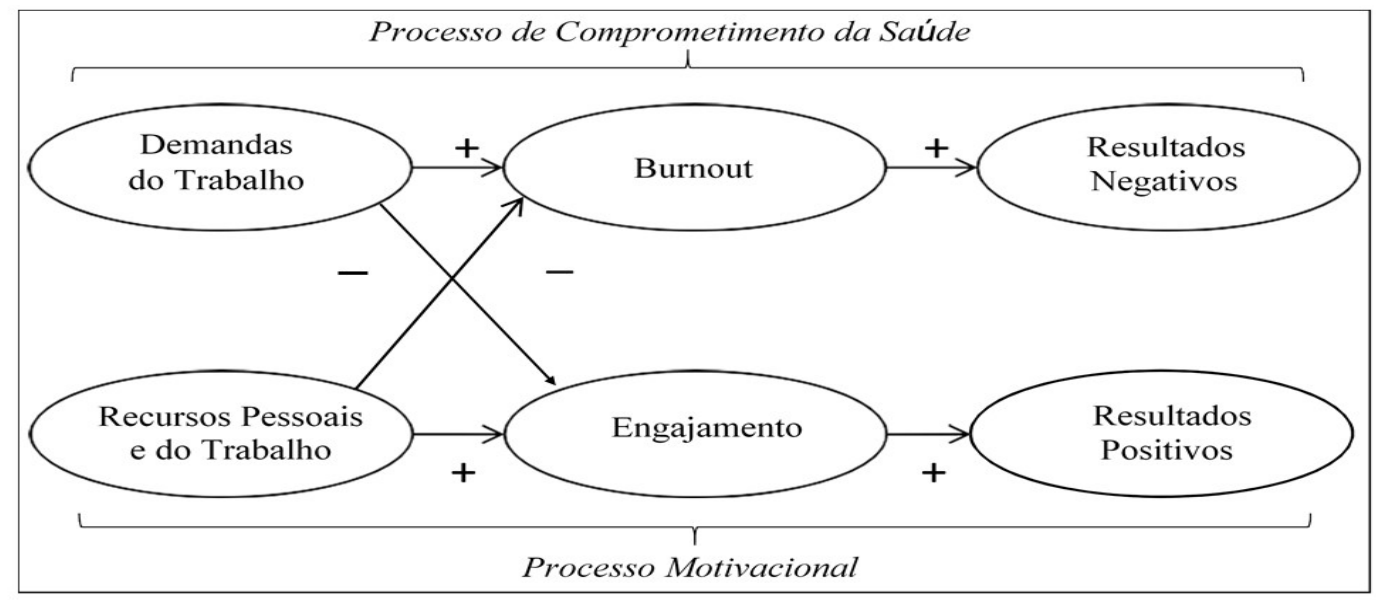

Figura 1. O Modelo de Recursos e Demandas do Trabalho. Elaborado pelos autores. Adaptado de "Applying the Job Demands-Resources model: a 'bow to' guide to measuring and tackling work engagement and burnout." de W. B. Schaufeli, 2017, Organizational Dynamics, 46(2), p. 122. Adaptado com permissão.

Nesse modelo teórico, o engajamento advém do equilíbrio ótimo entre recursos e demandas do trabalho, sendo o resultado da combinação dos recursos positivos de trabalho e pessoais, frente às exigências do cotidiano laboral. Os pesquisadores demonstram que o indivíduo se engaja devido às suas características de personalidade, de resiliência (Schaufeli \& Bakker, 2004), otimismo, autoeficácia, autoestima, entre outros (Ouweneel et al., 2012), aliadas com aspectos do trabalho, tais como: a integração com a equipe e com o gestor, o recebimento de feedbacks construtivos, sua autonomia laboral e condições de autodesenvolvimento profissional (Schaufeli et al., 2013).

Os estudos iniciais da Psicologia Organizacional Positiva defendem a influência dos aspectos positivos do contexto organizacional no engajamento dos empregados e, consequentemente, na prosperidade dos negócios (Bakker \& Schaufeli, 2008). Salanova, Agut, e Peiró (2005) realizaram um estudo com 120 funcionários da área de serviços (hotéis e restaurantes) e constataram que a fidelidade dos clientes ocorria em função do nível de engajamento coletivo dos colaboradores. Segundo o referido estudo, o engajamento desses colaboradores foi associado aos seus respectivos locais de trabalho, que apresentavam recursos organizacionais e recursos de trabalho positivos, percebidos pelos participantes da pesquisa como facilitadores do trabalho, tais como: clima, treinamentos, autonomia e tecnologia.

O clima organizacional de uma empresa pode apresentar-se sintomas psicossomáticos e insatisfação no trabalho (Schaufeli, 2016), além de consequências para a vida familiar e social e para o lazer (Carlotto \& Miralles, 2010). O mercado competitivo e a velocidade dos negócios podem levar as organizações a valorizar profissionais com dedicação integral ao trabalho. Isso pode incentivar a adição ao trabalho, sendo necessária maior investigação dessa possível associação (Carlotto \& Miralles, 2010). Tanto o engajado quanto o workaholic apresentam ativação pesada de energia no trabalho e ambos podem ser vistos como dedicados ao trabalho (Snir \& Harpaz, 2012), mas se faz necessária a distinção entre eles, devendo ser vistos, respectivamente, como investidores positivos e negativos, o bom e o mau investimento; de modo que a dimensão do prazer é fundamental para a taxonomia do bem-estar laboral (Salanova et al., 2014; Taris et al., 2014).

Ouweneel et al. (2012) demonstram que, ao longo do tempo, os funcionários que experimentam emoções positivas no trabalho têm maior propensão para esperança, otimismo e autoeficácia. Segundo Xanthopoulou et al. (2012), quanto mais elevados são os níveis de autoeficácia, autoestima e otimismo dos funcionários, maior é o sentimento de vivenciar emoções positivas durante um dia de trabalho. Nessa perspectiva, o profissional na área de $\mathrm{RH}$ precisa considerar o equilíbrio dos recursos e das demandas do trabalho para o seu desenvolvimento e dos demais colaboradores das organizações em que atua, integrando o uso do Modelo de RDT como demanda profissional, com o intuito de 
qualificar a gestão de pessoas dentro das organizações e, consequentemente, promover o engajamento dos indivíduos no trabalho (Albrecht, Bakker, Gruman, Macey, \& Saks, 2015). Foram formuladas, a partir dos principais estudos na área, quatro hipóteses:

H1. Profissionais de RH com maior autonomia têm engajamento mais elevado.

H2. Há associação positiva entre engajamento, autoestima, autoeficácia, otimismo e esperança.

H3. Há associação negativa entre engajamento e adição ao trabalho.

H4. Há relação entre engajamento e recursos e demandas do trabalho.

\section{Método}

\section{Participantes}

A população-alvo deste estudo foram os profissionais que atuam na área de Recursos Humanos $(\mathrm{RH})$, selecionada entre na rede profissional LinkedIn, que, em 13/12/2016, contava com 352.204 mil profissionais. Considerando para o cálculo do tamanho, uma estimativa parcimoniosa de 0,50 , como sendo a prevalência de engajamento, e uma diferença aceitável de 0,10, a fim de estimar intervalos de confiança de 95\% para esse parâmetro. Dessa forma, a amostra estimada foi de, pelo menos, 374 profissionais. Acrescentando $10 \%$ para possíveis perdas e recusas, a amostra final ficou em, pelo menos, 412 profissionais. Foram incluídos os profissionais de RH ativos no Brasil e que concordaram em participar por meio do Termo de Consentimento Livre e Esclarecido (TLCE). A amostra final totalizou 440 participantes, das cinco regiões brasileiras, com média de tempo de atuação em RH de aproximadamente 12 anos e de tempo na atual empresa de 5 anos (ver Tabela 1).

\section{Instrumentos}

Tratou-se de um estudo transversal, de natureza quantitativa que, para investigar e atender aos objetivos propostos, utilizou um questionário sociodemográfico com os dados apresentados na Tabela 1 e seis instrumentos psicométricos para investigar os constructos de engajamento, adição ao trabalho, autoeficácia, otimismo, esperança e autoestima.

Engajamento no trabalho. O engajamento foi mensurado pela versão brasileira da Utrecht Work Engagement Scale (UWES), adaptada e validada por Vazquez et al. (2016).

Adição ao trabalho. A adição ao trabalho foi avaliada pela versão brasileira da Dutch Workaholism Scale (DUWAS-10), adaptada e validada para o Brasil por Vazquez, Freitas, Cyrre, Hutz, e Schaufeli (2018).

Para analisar recursos pessoais de trabalho, foram aplicadas as seguintes escalas, todas adaptadas para o Brasil, $\operatorname{com} \alpha$ entre 0,70 e 0,89 :

EscaladeAutoeficáciaGeral.EscaladePacicoetal.(2014)que medeoquantooindivíduocrêquerealizarásuastarefasdeformaeficaz.

Versão brasileira da Revised Life Orientation Test (LOT-R). Escala de Bastianello e Pacico (2014) que avalia o otimismo, e que mensura, a partir de medidas, as expectativas individuais para eventos futuros.

Versão brasileira da Escala de Esperança Disposicional. Escala de Pacico e Bastianello (2014) que mede a capacidade do indivíduo de agenciamento de rotas para atingir um objetivo.

Versão brasileira da Escala de Autoestima de Rosenberger. Escala de Hutz et al., 2014) que mede o autoconceito de autoaprovação (positiva) ou de depreciação (negativo), por meio de um conjunto de pensamentos e sentimentos referentes a si mesmo.
Tabela 1

Descritiva da Amostra em Profissionais de $\mathrm{RH}$

\begin{tabular}{|c|c|}
\hline Características & $n(\%)$ \\
\hline \multicolumn{2}{|l|}{ Sexo } \\
\hline Feminino & $352(80,0)$ \\
\hline Masculino & $88(20,0)$ \\
\hline \multicolumn{2}{|l|}{ Região em que trabalha } \\
\hline Sul & $341(77,5)$ \\
\hline Sudeste & $77(17,5)$ \\
\hline Centro-Oeste & $7(1,6)$ \\
\hline Norte & $9(2,0)$ \\
\hline Nordeste & $6(1,4)$ \\
\hline \multicolumn{2}{|l|}{ Estado Civil } \\
\hline Solteiro & $261(59,3)$ \\
\hline Casado/ União Estável & $155(35,2)$ \\
\hline Separado & $22(5,0)$ \\
\hline Viúvo & $2(0,5)$ \\
\hline \multicolumn{2}{|l|}{ Escolaridade } \\
\hline Especialização & $261(59,3)$ \\
\hline Nível Superior & $123(28,0)$ \\
\hline Mestrado & $27(6,1)$ \\
\hline Ensino Técnico/Ensino Médio & $25(5,7)$ \\
\hline Doutorado & $4(0,9)$ \\
\hline \multicolumn{2}{|l|}{ Vínculo Trabalhista } \\
\hline Celetista & $335(76,1)$ \\
\hline Autônomo/Consultor Externo & $98(22,3)$ \\
\hline Serviço Público & $7(1,6)$ \\
\hline \multicolumn{2}{|l|}{ Função } \\
\hline Especialista/Analista & $212(48,2)$ \\
\hline Proprietário & $73(16,6)$ \\
\hline Gerente & $60(13,6)$ \\
\hline Supervisor & $54(12,3)$ \\
\hline Auxiliar & $29(6,6)$ \\
\hline Diretor & $12(2,7)$ \\
\hline \multicolumn{2}{|l|}{ Área de Atuação } \\
\hline $\begin{array}{l}\text { Desenvolvimento Organiza- } \\
\text { cional }\end{array}$ & $157(35,7)$ \\
\hline Generalista & $128(29,1)$ \\
\hline Administração Pessoal & $61(13,9)$ \\
\hline Consultoria Externa & $58(13,2)$ \\
\hline Gestão & $36(8,2)$ \\
\hline
\end{tabular}

Nota. Elaborado pelos autores.

\section{Procedimentos de Coleta de Dados e Cuidados Éticos}

O questionário deste estudo foi disponibilizado aos participantes por meio do SurveyMonkey, de agosto a novembro de 2017. Os profissionais elegíveis receberam o convite para o estudo através de um informante-chave, que foi o ponto de partida para o arrolamento dos participantes (snowball) pelo envio de e-mail, WhatsApp ou pelo contato via usuário no Linkedin. Todos receberam o link para o instrumento do estudo, que permitiu o preenchimento mediante o aceite do TCLE, no qual foi esclarecido que a participação seria voluntária, que se referia a um estudo sem qualquer efeito avaliativo individual e que as respostas e os dados referentes aos resultados eram anônimos e confidenciais. Foram seguidos os procedimentos éticos conforme a Resolução do Conselho Nacional de Saúde no 466/12, para o desenvolvimento de pesquisas que envolvem seres humanos. Teve aprovação pelo Comitê de Ética em Pesquisa da Uni- 
versidade Federal de Ciências da Saúde de Porto Alegre (CEP-UFCSPA) e foi registrado sob o número de parecer 2.034.167.

\section{Procedimentos de Análise de Dados}

Todos os dados foram compilados no SurveyMonkey e exportados para o SPSS v.23, garantindo, assim, o sigilo dos participantes e permitindo a descrição para caracterização da amostra estudada. Foram aplicadas as análises descritivas adequadas à natureza das variáveis. Para verificar a relação entre adição e recursos internos e externos elencados como relacionados com o engajamento no trabalho (variável principal do estudo), utilizamos o teste para comparação de médias e medianas, no caso das variáveis contínuas (os escores obtidos da avaliação de engajamento e demandas), e o teste qui-quadrado de independência para avaliar a associação das variáveis categóricas resultantes da classificação de engajamento e demandas do trabalho. Para todos os testes, foi adotado um nível de significância de 5\%.

\section{Resultados}

Os resultados foram organizados em duas partes. Primeiro, serão apresentadas e interpretadas as análises descritivas dos constructos engajamento, adição, autoestima, autoeficácia, otimismo e esperança, utilizando as comparações da média com os respectivos pontos médios das escalas destes. Segundo, serão apresentadas e interpretadas as associações e correlações de Pearson entre as variáveis para a validação das hipóteses.

Conforme demonstrado na Tabela 2, os profissionais de $\mathrm{RH}$ apresentam nível de engajamento médio e, quanto às suas dimensões, encontram-se dedicação nível médio, vigor médio-inferior e concentração nível baixo. Já os recursos pessoais apresentam para a autoeficácia nível médio-superior para mulheres e nível médio para homens e, ainda, níveis médios para autoestima, otimismo e esperança. O nível de adição foi médio, apresentando níveis medianos para as dimensões Trabalho Excessivo (TE) e Trabalho Compulsivo (TC). Esses resultados mostram profissionais, ao mesmo tempo, engajados e workaholics; por isso, é necessário avaliar a forma de ativação da energia, com a possibilidade de ativar as dimensões de vigor e de concentração para a elevação do constructo de engajamento, cuidando para evitar o TE e o TC, a fim de prevenir o aumento da adição ao trabalho e, consequentemente, evitar riscos ao bem-estar e à saúde laboral.

Tabela 2

Descritiva dos Constructos Engajamento, Adição e Recursos Pessoais

\begin{tabular}{lcccc}
\hline \multicolumn{1}{c}{ Constructo } & Mínimo & Máximo & $M(D P)$ & Percentil $^{(a)}$ \\
\hline Engajamento & 1,1 & 6,0 & $4,46(0,9)$ & 45 \\
Dedicação & 0,6 & 6,0 & $4,67(1,1)$ & 50 \\
Vigor & 1,2 & 6,0 & $4,46(0,9)$ & 40 \\
Concentração & 0,7 & 6,0 & $4,27(0,9)$ & 35 \\
Adição & 1,0 & 4,0 & $2,28(0,6)$ & 55 \\
Trabalho Excessivo & 1,0 & 4,0 & $2,57(0,6)$ & 55 \\
Trabalho Compulsivo & 1,0 & 4,0 & $2,00(0,7)$ & 60
\end{tabular}

Recursos Pessoais

\begin{tabular}{lcccc} 
Autoeficácia & 41,0 & 100,0 & $78,05(8,9)$ & $70 / 60^{\text {(b) }}$ \\
Autoestima & 13,0 & 40,0 & $33,99(4,2)$ & 55 \\
Esperança & 19,0 & 40,0 & $32,96(3,5)$ & 60 \\
Otimismo & 12,0 & 30,0 & $23,99(3,7)$ & 45 \\
\hline
\end{tabular}

Nota. Elaborado pelos autores. ${ }^{(a)}$ Percentil de correção dos instrumentos. ${ }^{(b)}$ Percentil mulheres $=70$; homens $=60$.

Analisando as variáveis sociodemográficas do estudo para engajamento, não foram encontradas diferenças significativas $(p$
$<$,001) quanto ao gênero, estado civil, escolaridade ou regiões do país. Destaca-se que o engajamento foi o mais elevado, de acordo com o crescimento do nível da escolaridade. Encontrou-se nível médio de engajamento para os níveis de Doutorado $(M=4,80$; $D P=2,0 ;$ percentil 55), Mestrado $(M=4,77 ; D P=0,6$; percentil $50)$ e Especialização ou MBA $(M=4,54 ; D P=0,9$; percentil 40$)$; e nível baixo para Ensino Superior $(M=4,23 ; D P=1,0$; percentil 35) e Ensino Técnico ou Médio ( $M=4,22 ; D P=0,9$; percentil 35).

Os resultados de engajamento versus as variáveis de função, a área de atuação e o vínculo de trabalho demonstram que participantes que sugerem maior autonomia laboral apresentam níveis mais elevados de engajamento, confirmando H1. A ANOVA mostrou diferença estatisticamente significativa na média de engajamento entre os grupos dessas variáveis $(p<, 001)$.

Nos achados, evidenciou-se que o índice de engajamento vai gradualmente aumentando quanto maior a hierarquia do cargo, apresentando maior engajamento os profissionais com cargos de gestão e proprietários, funções que sugerem maior autonomia para tomada de decisão (Magnan, Vazquez, Pacico, \& Hutz, 2016). As médias de engajamento mostraram que os profissionais mais engajados são os donos de seus próprios negócios, os proprietários com nível mais elevado, com engajamento médio-superior $(M=5,08$; $D P=0,5$; percentil 65), seguidos pelo engajamento médio de diretor $(M=4,82 ; D P=0,6$; percentil 55$)$ e de gerente $(M=4,63 ; D P$ $=0,7$; percentil 45$)$. As médias de engajamento vão decrescendo nas funções técnicas ou operacionais; sendo assim, encontramos nível médio-inferior do supervisor $(M=4,42 ; D P=0,7$; percentil 40) e engajamento baixo do especialista ou analista $(M=4,26 ; D P$ $=1,0$; percentil 35) e do auxiliar $(M=4,82 ; D P=1,0$; percentil 25).

A autonomia também se confirma, analisando a área de atuação dos profissionais. Os que atuam como consultores externos autônomos $(M=4,80 ; D P=0,9$; percentil 55) e como gestores $(M=4,70 ; D P=0,7$; percentil 50$)$ apresentam engajamento médio mais elevado que os indivíduos que se declaram generalistas $(M=4,48 ; D P=0,8$; percentil 40). $\mathrm{Na}$ área de desenvolvimento organizacional $(M=4,38 ; D P=1,0$; percentil 40$)$, vinculados a uma organização, ambos apresentam nível de engajamento médio-inferior. Nota-se que os indivíduos que atuam na área de administração de pessoal - comumente mais operacional, sendo responsável pelos processos de folha de pagamentos, documentação de pessoal, admissões e desligamentos - apresentam baixo engajamento $(M=4,19 ; D P=1,0$; percentil 35$)$. Quanto ao vínculo trabalhista, evidencia-se novamente influência da autonomia, visto que aqueles que se declararam autônomos (trabalhador pessoa jurídica) apresentaram engajamento nível médio ( $M$ $=4,92 ; D P=0,7$; percentil 60$)$. O engajamento foi baixo para trabalhadores com contrato laboral regido pela Consolidação das Leis do Trabalho (CLT) $(M=4,32 ; D P=0,9$; percentil 35) e para os servidores públicos $(M=4,08 ; D P=0,9$; percentil 30).

Considerando os estudos para validação da escala de UWES brasileira que encontraram relação significativa entre engajamento e faixa etária laboral, com tabelas de interpretação específicas, os participantes foram distribuídos em grupos de idade de acordo com a etapa de carreira: de 18 a 28 anos, início da vida laboral; de 29 a 39 anos, fase de desenvolvimento e, a partir dos 40 anos, fase de consolidação profissional (Vazquez et al., 2016). Então, o grupo na fase de desenvolvimento apresentou nível médio-inferior de engajamento $(M=4,43 ; D P=0,9$; percentil 40), estando mais elevado que os grupos que estão no início de carreira $(M=4,10 ; D P=1,0$; percentil 30) ou na fase de consolidação $(M=4,74 ; D P=0,8$; percentil 35$)$ de carreira, que apresentaram baixo nível de engajamento. A ANOVA confirmou diferença significativa entre os grupos etários $(p<, 001)$.

O baixo engajamento para faixa etária de 18 a 28 anos é espe- 
rado, pois o início de carreira oferta poucas chances de autonomia, que é preditor do engajamento. Já para a faixa etária acima de 40 anos com baixo nível de engajamento, esperava-se que o engajamento aumentasse devido à consolidação da carreira, mas isso não aconteceu e, portanto, vai contra as expectativas deste estudo. Para melhor compreensão do fenômeno, analisando o grupo ocupacional dos participantes acima de 40 anos $(n=136)$, os resultados apresentados na Tabela 3 sugerem que, nesse grupo, só os proprietários apresentam engajamento médio-superior, seguidos de engajamento médio do diretor e do gerente. O nível de engajamento baixa à medida que os cargos possuem caráter técnico e/ou operacional, como é o caso do supervisor (comum para denominar chefia técnica). Especialista e analista apresentaram nível médio-inferior, e auxiliar apresentou baixo engajamento. Estes representam 39\% deste público. Também se evidencia que a autonomia se associa ao tipo de vínculo de trabalho: os autônomos apresentam engajamento médio, enquanto celetistas e servidores públicos, nível baixo de cou associação negativa entre engajamento e adição ao trabalho; neste estudo foi encontrada correlação positiva, mas considerada fraca. Já a relação entre engajamento e recursos e demandas do trabalho foi confirmada; identificamos nesse grupo avaliado associação positiva de engajamento com recursos do trabalho e negativa com demandas. E a adição ao trabalho apresentou uma associação positiva com demandas e negativa com recursos.

\section{Discussão}

O principal objetivo deste estudo foi avaliar o nível de engajamento e de adição ao trabalho e suas correlações com recursos pessoais, recursos do trabalho e demandas no trabalho em profissionais de RH. De modo geral, os achados revelaram que os profissionais participantes possuem nível médio de engajamento com níveis medianos dos recursos pessoais investigados e com nível médio de adição ao trabalho, TC e TE. Os resultados obtidos sugerem que

Tabela 3

Descritiva dos Constructos Engajamento, Dedicação, Vigor e Concentração de Acordo com o Perfil Ocupacional para Faixa Etária Acima de 40 Anos

\begin{tabular}{|c|c|c|c|c|c|}
\hline \multirow[b]{2}{*}{ Perfil Ocupacional } & \multirow[b]{2}{*}{$n(\%)$} & Engajamento & Dedicação & Vigor & Concentração \\
\hline & & \multicolumn{4}{|c|}{$M \pm D P$ (percentil) } \\
\hline \multicolumn{6}{|l|}{ Função } \\
\hline Proprietário & $50(36,8)$ & $5,11 \pm 0,6(70)$ & $5,38 \pm 0,7(70)$ & $5,15 \pm 0,6(55)$ & $4,85 \pm 0,7(45)$ \\
\hline Especialista/Analista & $30(22,1)$ & $4,39 \pm 1,0(40)$ & $4,57 \pm 1,2(25)$ & $4,40 \pm 0,9(25)$ & $4,23 \pm 0,9(30)$ \\
\hline Gerente & $23(16,9)$ & $4,83 \pm 0,5(50)$ & $5,10 \pm 0,7(40)$ & $4,90 \pm 0,6(45)$ & $4,52 \pm 0,5(35)$ \\
\hline Supervisor & $21(15,4)$ & $4,38 \pm 0,7(40)$ & $4,65 \pm 1,1(30)$ & $4,33 \pm 0,8(25)$ & $4,21 \pm 0,8(30)$ \\
\hline Diretor & $10(7,4)$ & $4,74 \pm 0,7(50)$ & $4,82 \pm 1,1(35)$ & $4,98 \pm 0,7(45)$ & $4,43 \pm 0,7(45)$ \\
\hline Auxiliar & $2(1,5)$ & $3,38 \pm 0,4(20)$ & $3,70 \pm 0,1(15)$ & $3,50 \pm 0,7(15)$ & $3,00 \pm 0,2(10)$ \\
\hline \multicolumn{6}{|l|}{ Área de Atuação } \\
\hline Consultoria Externa & $39(28,7)$ & $5,01 \pm 0,6(45)$ & $5,32 \pm 0,7(45)$ & $5,02 \pm 0,6(45)$ & $4,73 \pm 0,7(40)$ \\
\hline Generalista & $33(24,3)$ & $4,58 \pm 0,7(30)$ & $4,87 \pm 1,0(30)$ & $4,62 \pm 0,8(35)$ & $4,29 \pm 0,7(30)$ \\
\hline DO & $27(19,9)$ & $4,39 \pm 0,6(30)$ & $4,95 \pm 1,1(35)$ & $4,85 \pm 0,7(40)$ & $4,68 \pm 0,7(40)$ \\
\hline $\mathrm{AP}$ & $20(14,7)$ & $4,21 \pm 1,0(20)$ & $4,39 \pm 1,3(20)$ & $4,25 \pm 1,0(20)$ & $4,03 \pm 1,1(25)$ \\
\hline Gestão & $17(12,5)$ & $4,89 \pm 0,7(40)$ & $5,11 \pm 0,7(40)$ & $4,98 \pm 09(45)$ & $4,62 \pm 0,7(40)$ \\
\hline \multicolumn{6}{|l|}{ Vínculo Trabalhista } \\
\hline Celetista & $71(52,2)$ & $4,53 \pm 0,8(25)$ & $4,51 \pm 1,1(45)$ & $4,34 \pm 1,0(40)$ & $4,15 \pm 1,0(30)$ \\
\hline Autônomo & $61(44,9)$ & $5,02 \pm 0,6(45)$ & $5,22 \pm 0,8(70)$ & $4,90 \pm 0,8(60)$ & $4,69 \pm 0,7(50)$ \\
\hline Serviço Público & $4(2,9)$ & $4,30 \pm 0,8(20)$ & $4,20 \pm 1,2(35)$ & $4,14 \pm 0,8(30)$ & $3,92 \pm 0,8(30)$ \\
\hline
\end{tabular}

Nota. DO = Desenvolvimento Organizacional, AP = Administração Pessoal. Elaborado pelos autores.

engajamento. Para esta faixa etária, confirma-se novamente H1.

Como observado na Tabela 4 , em relação às hipóteses H2, H3 e H4, há associação positiva entre engajamento e autoestima, autoeficácia, otimismo e esperança, foi confirmada. Foi encontrada correlação média de engajamento com autoestima, autoeficácia e otimismo; e forte correlação com esperança. Não se verifiTabela 4

Coeficientes de Correlação de Pearson entre os Atributos Descritos $(n=440)$

\begin{tabular}{|c|c|c|c|c|c|c|c|c|c|}
\hline Atributos & 1 & 2 & 3 & 4 & 5 & 6 & 7 & 8 & 9 \\
\hline 1. Demandas & - & & & & & & & & \\
\hline 2. Recursos &,$- 33 * *$ & - & & & & & & & \\
\hline 3. Autoeficácia &,$- 13^{* *}$ &, $22 * *$ & - & & & & & & \\
\hline 4. Autoestima &,$- 16^{* *}$ &, $23^{* *}$ &, $65^{* *}$ & - & & & & & \\
\hline 5. Esperança &,$- 11 *$ &, $31 * *$ &, $73^{* *}$ &, $53^{* *}$ & - & & & & \\
\hline 6. Otimismo &,$- 16^{* *}$ &, $25^{* *}$ &, $61^{* *}$ &, $59 * *$ &, $55^{* *}$ & - & & & \\
\hline 7. Engajamento &,$- 17 * *$ &, $52^{* *}$ &, $45^{* *}$ &, $34^{* *}$ &, $46^{* *}$ &, $33 * *$ & - & & \\
\hline 8. Adição &, $42^{* *}$ &,- 08 &,- 01 &,$- 13^{*}$ &, 08 &,- 08 &, $14^{* *}$ & -- & \\
\hline 9. Trabalho Excessivo &, $42 * *$ &,- 01 & ,05 &,- 03 &, $13^{*}$ &,- 02 &, $21 * *$ &, $90 * *$ & - \\
\hline 10. Trabalho Compulsivo &, $35 * *$ &,$- 13^{* *}$ &,- 06 &,$- 19 * *$ & 03 &,$- 12 *$ & 06 &, $93^{* *}$ & $66^{* *}$ \\
\hline
\end{tabular}

Nota. Elaborado pelos autores. $* p<, 05, * * p<, 01$. tais profissionais relacionam positivamente seu engajamento com níveis maiores nos recursos pessoais de autoestima, autoeficácia, otimismo e esperança, ao mesmo tempo em que o nível de adição ao trabalho representa um risco eminente de desgaste da energia laboral pelo TE e TC, que caracterizam o comportamento desses trabalhadores. Embora baixa, a correlação entre engajamento e 
adição foi positiva para nestes profissionais. De encontro ao esperado, essa associação apresenta um quadro preocupante por relacionar aspectos da vinculação de energia com propósitos de realização e prazer a aspectos de compulsividade e excesso de trabalho.

Para engajamento, os escores medianos são o esperado e expressam o balanceamento entre recursos e demandas (Vazquez et al., 2016), e os níveis alto ou baixo podem ser explicados por meio da relação com os níveis de cada dimensão (Magnan et al., 2016). Então, analisando os resultados dos participantes deste estudo, os profissionais de RH corroboram com o esperado para engajamento, sugerindo que são intrinsicamente motivados para o trabalho, engajados em sua atividade laboral por considerá-la interessante, agradável e satisfatória, influenciados pelos aspectos positivos motivacionais encontrados nas características autoestima, eficácia e otimismo com o futuro e esperança (Ouweneel et al., 2012; Taris et al., 2014). Além disso, percebe-se a influência das dimensões para o nível global do constructo, sendo este classificado como médio, pelo impacto do nível médio-inferior de vigor e nível baixo de concentração, o que indica redução de energia e baixo foco e pode estar associado ao TE e TC.

Ainda a respeito dos recursos, foi encontrada associação positiva e forte de engajamento entre recursos do trabalho e, enquanto positiva e moderada entre autoeficácia, autoestima, esperança e otimismo. Também ocorreu associação negativa entre engajamento e recursos e demandas do trabalho, confirmando $\mathrm{H} 2$ e H4. Ademais, os profissionais de RH com maior autonomia em sua função, área de atuação e/ou vínculo de trabalho apresentaram o engajamento mais elevado, confirmando H1. Dentre as variáveis, o nível mais elevado foi o engajamento médio-superior do proprietário (dono do seu negócio, sem reporte de subordinação), seguido por escores medianos de diretores e gerentes e por escore médio inferior dos supervisores, representando 45\% da amostra. Esse dado corrobora estudos anteriores do Modelo de RDT, para o qual a autonomia é um recurso do trabalho que influencia diretamente no engajamento (Albrecht et al., 2015) e é uma necessidade psicológica básica inerente ao seres humanos que, quando atendida pela liderança, promove trabalhadores engajados (Schaufeli, 2017).

Preocupa que a maior parte da amostra, 55\%, composta de $48 \%$ de especialistas/analistas e $7 \%$ de auxiliares, apresenta baixo engajamento, o que influencia o escore geral da área de RH. Os profissionais que estão na linha de frente com os colaboradores demonstraram baixa energia, pouca persistência, falta de orgulho e dificuldade de absorção ao trabalho. Considerando o tipo de vínculo, o dado torna-se mais preocupante quanto ao engajamento dos participantes que atuam com vínculo empregatício em organizações privadas e públicas, de modo que $78 \%$ da amostra apresentaram nível baixo de engajamento, sendo $76 \%$ celetistas/trabalhadores e $2 \%$ servidores públicos. Somente os autônomos apresentaram nível médio de engajamento (22\%).

No que diz respeito à faixa etária laboral, os resultados foram conforme o esperado para início e desenvolvimento de carreira; já para a fase de consolidação, esperava-se que o nível de engajamento fosse maior a partir dos 40 anos, o que não ocorreu neste estudo, uma vez que este grupo apresentou baixo engajamento. Para Schaufeli et al. (2013), à medida que os profissionais amadurecem, procuram assumir atividades profissionais que atendam aos seus desejos, maiores desafios, responsabilidade e autonomia. Nota-se que participantes acima de 40 anos que chegaram a esta fase como proprietários possuem o nível mais elevado tanto em comparação à sua função na amostra geral (ambos médio-superior, mas o percentil sobe de 65 para 70, mais próximo do alto engajamento) quanto em relação às outras funções. Deste modo, confirmando o encontrado em H1, quanto maior a autonomia do cargo, mais elevado é o engajamento. Não obstante, os resultados para su- pervisores, especialistas/analistas (percentil 40, médio-inferior) e auxiliares (percentil 20, baixo) sugerem que esses, ao chegarem a essas posições em sua vida profissional, almejam ser mais valorizados financeiramente ou realizar atividades mais estratégicas, com maiores desafios e autonomia. Os achados indicam que há possibilidade, por frustração e falta de perspectivas, de os profissionais acima de 40 anos terem diminuído seu grau de engajamento.

Para compreender em maior profundidade esse contraste com o esperado nos estudos da área, foram analisados os $74 \%$ que ocupam posições de cargo de gestão, sugerindo autonomia e adequados níveis de recursos pessoais; sendo assim, esperavam-se níveis superiores de engajamento. Pode-se inferir que os resultados estejam afetados negativamente pela instabilidade econômica dos últimos anos, exigindo fechamento de vagas, redução de quadro de pessoal e de salários - demandas que ficam sob a responsabilidade do RH. É possível supor também que a escassez de recursos do trabalho nos ambientes organizacionais não esteja favorecendo uma cultura de desenvolvimento, mas sim uma valorização do excesso de trabalho no desenho das tarefas para tais profissionais. Essas situações podem levar à descrença desses indivíduos nas organizações e a frustações devido à dificuldade de realizar as melhores práticas de gestão com pessoas ou de ocupar um papel mais estratégico. Em sendo assim, faz-se necessário aprofundar estudos sobre recursos e demandas do trabalho e perspectivas de carreira para essa faixa etária.

De maneira díspare, H3 não foi confirmada. Conforme já citado, os profissionais de $\mathrm{RH}$, diferente dos achados científicos, demonstraram uma correlação positiva e fraca entre engajamento e adição ao trabalho. Destaca-se que a associação positiva do engajamento com adição ao trabalho relaciona-se com o grau médio de TE e TC encontrado, visto que o comportamento de compulsão em suas atividades laborais foi evidenciado nesse estudo. O TE não corrobora com a autodeclaração dos participantes de laborarem semanalmente uma média de 45,11 horas, o que não se caracteriza como algo elevado, já que a legislação permite jornada de trabalho de 44h, podendo ser acrescida de duas horas extras diárias.

Já que o trabalho é percebido pelos participantes como excessivo e de comportamento compulsivo, tais evidências sugerem que há indicativos de possível adoecimento associado a distúrbios, emoções negativas, irritabilidade, ansiedade, culpa e vergonha presentes nos workaholics. Esses comportamentos são prejudiciais à saúde, diminuindo a felicidade e a qualidade das relações pessoais e sociais (Taris et al., 2014). Por outro lado, pode-se inferir que o TE pode influenciar o nível médio-inferior de vigor e o risco desse fator psicossocial - enquanto processo estressor no contexto de trabalho - ocorrer, pois está presente em sua vida laboral; o qual pode se associar, em algum momento, a agravos como o distress ou o Burnout, apresentando potencial de gerar afastamentos e outros danos à saúde desses trabalhadores.

Além disso, segundo Taris et al. (2014), engajamento e adição ao trabalho são duas formas de investimento pesado de energia no trabalho, referindo-se ao tempo e ao esforço dedicados. Os autores destacam que, apesar de conceitos diferentes e independentes, com disparidades na relação com resultados, tanto o trabalhador engajado quanto o adicto podem parecer produtivos para quem os observa. Ambos apresentam características comuns de personalidade, tais como: narcisismo, autodeterminação e extroversão, e diferenças associadas ao neuroticismo (associado ao workaholic), à estabilidade emocional e à agradabilidade (associadas ao engajado). Considerando que características do ambiente podem determinar o tipo de investimento pesado no trabalho, o comportamento, como uma resposta da personalidade ao ambiente, manifesta a combinação entre as diferenças na personalidade e as situações vividas.

Importante ressaltar que os estudos demonstram que ser 
adicto ao trabalho não significa ser mais produtivo; ao contrário, devido à probabilidade de adoecimento (Taris et al., 2014). Então, pode-se inferir que, para parecerem mais produtivos, esses profissionais perdem energia e diminuem concentração como uma consequência do desenho do trabalho organizado para eles, em razão da pluralidade de atividades e da necessidade de envolver e atender aos demais profissionais das organizações, sendo mais exigida a dedicação (dimensão mais elevada), com maior conexão e entusiasmo com trabalho e tarefas que realizam, devido ao significado que atribuem a este e, por isso, o sentimento de orgulho. A longo prazo, isso prejudica a maior ativação de energia, impedindo níveis mais elevados de engajamento, o que pode estar associado a características da personalidade que são percebidas e valorizadas como "produtivas" e fortalecidas pelo ambiente de RH e das organizações, fazendo-se necessários maiores estudos a respeito.

Além disso, seguindo a recomendação de Albrecht et al. (2015), os profissionais de RH precisam ir além da administração da rotina, integrando o uso do Modelo de RDT para a gestão de pessoas, para melhorar o engajamento dos funcionários por meio das práticas de RH (seleção, socialização, gerenciamento de desempenho, treinamento) e de intervenções para o equilíbrio das demandas e dos recursos do trabalho e desenvolvimento dos recursos pessoais.

A partir de seus achados, este estudo faz uma provocação aos profissionais da área, pois, para conseguir fazer esse "ir além”, será necessário ativar os próprios recursos pessoais; por exemplo, elevar o otimismo poderia ajudar a perceber oportunidades na carreira e ver propósito no papel social que desempenham para o desenvolvimento humano e para a promoção de saúde e bem-estar. Outro aspecto importante é buscar o equilíbrio entre recursos e demandas em suas atividades, reduzindo o excesso de trabalho, a fim de propiciar um ambiente laboral saudável para os profissionais de $\mathrm{RH}$ e, assim, promover a cultura do engajamento na gestão de pessoas, para que todos os trabalhadores encontrem realização e felicidade no trabalho.

Este estudo é o primeiro no Brasil, no momento em que realizamos nossa revisão sobre os temos, que busca relacionar o constructo do engajamento e da adição no trabalho em profissionais de RH, o que limitou a possibilidade de comparação dos resultados. Além disso, a amostra predominante do sexo feminino e a concentração na região sul podem comprometer a generalização dos resultados, fazendo-se necessários novos estudos a respeito. Para estudos futuros, sugere-se, quanto ao achado para participantes a partir dos 40 anos, que se explorem os impactos a respeito de recursos e demandas do trabalho e perspectivas de carreira para essa faixa etária, a fim de identificar os motivos para o nível de engajamento encontrado.

Referente ao achado da associação positiva entre engajamento e adição ao trabalho, faz-se necessário aprofundar a investigação sobre a percepção de TE e TC, a influência das características da personalidade e do ambiente organizacional, bem-estar e estresse para esses profissionais. Considera-se, também, que é importante realizar estudos sobre as correlações do engajamento no trabalho com o impacto do clima ou dos resultados organizacionais, aspectos relevantes para a gestão de pessoas. Sugere-se, por fim, que, em estudos futuros, busque-se compreender as melhores práticas para a gestão de pessoas que promovam também o prazer, a realização e o bem-estar no trabalho.

\section{Referências}

Albrecht, S. L., Bakker, A. B., Gruman, J. A., Macey, W. H., \& Saks, A. M. (2015) Employee engagement, human resource management practices and competitive advantage: an integrated approach. Journal of Organizational Effectiveness: People and Performance, 2(1), 7-35. https://doi.org/10.1108/JOEPP-08-2014-0042
Bakker, A. B., \& Schaufeli, W. B. (2008). Positive organizational behavior: engaged employees in flourishing organizations. Journal of Organizational Behavior, 29(2), 147-154. https://doi.org/10.1002/job.515

Bastianello, M. R., \& Pacico, J. C. (2014). Otimismo. Em C. S. Hutz (Org.), Avaliação em psicologia positiva (pp. 95-100). Porto Alegre: Artmed.

Carlotto, M. S., \& Miralles, M. D. L. (2010). Tradução, adaptação e exploração de propriedades psicométricas da Escala de Adição ao Trabalho Dutch Work Addiction Scale (DUWAS). Contextos Clinicos, 3(2), 141-150. https://doi. org $/ 10.4013 /$ ctc. 2010.32 .08

Conselho Nacional de Saúde (2012). Resolução no 466/2012 - Dispõe sobre pesquisa envolvendo seres humanos. Brasil: Ministério da Saúde, Brasília, DF.

Hutz, C. S., Zanon, C., \& Vazquez, A. C. S. (2014). Escala de Autoestima de Rosenberg. Em C. S. Hutz (Org.), Avaliação em psicologia positiva (pp. 85-94). Porto Alegre: Artmed.

Magnan, E. S., Vazquez, A. C. S., Pacico, J. C., \& Hutz, C. S. (2016). Normatização da versão brasileira da Escala de Utrecht de Engajamento no Trabalho. Avaliação Psicológica, 15(2), 133-140. https://doi.org/10.15689/ ap.2016.1502.01

Ouweneel, E., Le Blanc, P. M., \& Schaufeli, W. B. (2012). Don’t leave your heart at home: Gain cycles of positive emotions, resources, and engagement at work. Career Development International, 17(6), 537-556. https://doi. org/10.1108/13620431211280123

Pacico, J. C., \& Bastianello, M. R. (2014). Instrumentos para avaliação da esperança: Escala de esperança disposicional e escala da esperança cognitiva. Em C. S. Hutz (Org.), Avaliação em psicologia positiva (pp.101-110). Porto Alegre: Artmed.

Pacico, J. C., Ferraz, S. B., \& Hutz, C. S. (2014). Autoeficácia - Yes we can! In C. S. Hutz (Org.), Avaliação em psicologia positiva (pp. 111-119). Porto Alegre: Artmed.

Salanova, M., Agut, S., \& Peiró, J. M. (2005). Linking organizational resources and work engagement to employee performance and customer loyalty: The mediation of service climate. Journal of Applied Psychology, 90(6), 1217-1227. https://doi.org/10.1037/0021-9010.90.6.1217

Salanova, M., Del Líbano, M., Llorens, S., \& Schaufeli, W. B. (2014). Engaged, workaholic, burned-out or just 9-to-5? Toward a typology of employee well-being. Stress and Health, 30(1), 71-81. https://doi.org/10.1002/smi.2499

Schaufeli, W. B. (2016). Heavy work investment, personality and organizational climate. Journal of Managerial Psychology, 31(6), 1057-1073. https://doi. org/10.1108/JMP-07-2015-0259

Schaufeli, W. B. (2017). Applying the Job Demands-Resources model: a 'how to' guide to measuring and tackling work engagement and burnout. Organizational Dynamics, 46(2), 120-132. https://doi.org/10.1016/j.orgdyn.2017.04.008

Schaufeli, W. B. (2018). O que é engajamento? Em A. C. S. Vazquez \& C. S. Hutz (Orgs.), Aplicações da psicologia positiva, trabalho e organizações (pp. 33-62). São Paulo: Hogrefe.

Schaufeli, W. B., \& Bakker, A. B. (2004). Job demands, job resources, and their relationship with burnout and engagement: A multi-sample study. Journal of Organizational Behavior, 25(3), 293-315. https://doi.org/10.1002/job.248

Schaufeli, W. B., \& Bakker, A. B. (2010). The conceptualization and measurement of work engagement. Em A. B. Bakker \& M. P. Leiter (Eds.), Work engagement: a handbook of essential theory and research (pp. 10-24). New York: Psychology Press.

Schaufeli, W. B., Dijkstra, P., \& Vazquez, A. C. S. (2013). Engajamento no trabalho. São Paulo: Casa do Psicólogo.

Seligman, M. E. (2012). Florescer: uma nova compreensão da felicidade e do bem-estar. Rio de Janeiro: Objetiva.

Snir, R., \& Harpaz, I. (2012). Beyond workaholism: Towards a general model of heavy work investment. Human Resource Management Review, 22(3), 232-243. https://doi.org/10.1016/j.hrmr.2011.11.011

Taris, T. W., Van Beek, I., \& Schaufeli, W. (2014). The beauty versus the beast: on the motives of engaged and workaholic employees. Em I. Harpaz \& R. Snir. Heavy work investment: its nature, sources, outcomes, and future directions (pp. 121-139). New York: Taylor and Francis.

Vazquez, A. C. S., Freitas, C. P. P., Cyrre, A., Hutz, C. S., \& Schaufeli, W. B. (2018). Evidências de validade da versão brasileira da escala de workaholism (DUWAS-16) e sua versão breve (DUWAS-10). Avaliação psicológica, 17(1), 69-78. https://doi.org/10.15689/ap.2017.1701.08.13288

Vazquez, A. C. S., Pacico, J. C., Magnan, E., Hutz, C. S., \& Schaufeli, W. B. (2016). Avaliação do engajamento das pessoas com seu trabalho: a versão brasileira da escala Utrecht de engajamento (UWES). Em C. S. Hutz (Org.), Avaliação em psicologia positiva (pp. 75-89). São Paulo: Hogrefe.

Xanthopoulou, D., Bakker, A. B., Demerouti, E., \& Schaufeli, W. B. (2012). A diary study on the happy worker: How job resources generate positive emotions and personal resources. European Journal of Work \& Organizational Psychology, 21(4), 489-517. https://doi.org/10.1080/1359432X.2011.584386 
* Informações sobre os autores

\section{Claudia Duarte Vergara}

UFCSPA, Rua Sarmento Leite, 245, Bairro: Centro - Porto Ale-

gre, Rio Grande do Sul, Brasil, CEP 90050-170.

E-mail: claudiaduarte_vergara@hotmail.com

\section{Augusto Gilmar Antunes Althoff}

E-mail: augustoalthoff11@gmail.com

\section{Luana Giongo Pedrotti}

E-mail: luana.pedrotti@ufrgs.br

\section{Ana Claudia Souza Vazquez}

E-mail: vazquez.ac@gmail.com

Mônica Maria Celestina De Oliveira

E-mail: monica.ufcspa@gmail.com 